\title{
Correspondence
}

\section{Another greetings survey?}

Vinjamuri et al ${ }^{1}$ point out that there has been little research into patients' preferences about how they are greeted by their psychiatrist. I have discovered that there is virtually nothing published on how we should greet those with whom we work, and the issues are similar.

It is quite common for paramedical staff to be addressed by their first names by doctors, especially consultants, who seem to expect to be called by their title in return. As a trainee, I have been struck by how often, without asking, I am greeted by my first name by seniors in rank, but often not in age, who expect me to use their title when speaking to them. It is hardly surprising then that this sort of power imbalance is perpetuated in our dealings with patients.

It is worth noting that the 1982 edition of the classic book on polite behaviour, Debrett's Etiquette and Modern Manners, ${ }^{2}$ is quite clear on forms of address in business: 'The use of Christian names should work both ways except where there is a substantial age gap. It is arrogant of a superior to choose to be addressed formally, yet to call subordinates by their first names (or by last names only).' We would do well to remember this and extend this to all with whom we come into contact.

1 Vinjamuri IS, Nehal MAM, Latt MM. Greetings survey (letter). Psychiatr Bull 2009; 33: 313.

2 Burch DE. Debrett's Etiquette and Modern Manners: 254. Pan Books, 1982.

James C. Allen is Specialty Registrar in Psychiatry, Hartington Unit, Chesterfield Royal Hospital, UK, email: james.c.allen@doctors.org.uk doi: $10.1192 / \mathrm{pb} .34 .1 .36$

\section{Crisis team fidelity in Wessex}

We conducted a small-scale survey to investigate the management and operational procedures of local crisis teams within the Wessex Deanery in a similar vein to the 2006 national survey. These findings were compared with the Department of Health's Guidance Statement. ${ }^{2}$

A senior practitioner or team manager from local crisis teams completed a form on their respective case-load, staffing, available resources and the service they provide. We were particularly interested to see whether the teams had dayhospital facilities and whether they provided services outside the 16-65 year age group as outlined by the Department of Health. ${ }^{3}$ We compared the results with the national survey data.

Six out of the nine teams responded. All provided a 24-hour service and gate-keep in-patient beds, significantly more than what the national survey showed ( $72 \%$ of teams gate-keep in-patient beds and 53\% provided a 24 -hour service).

Only 33\% (two teams) provided a service for 16- to 65year-olds, with the rest covering 18- to 65-year-olds. Outside this scope, half (three teams) provide services for individuals with intellectual disability and only $17 \%$ (one team) for older persons. Only one team had a day hospital.

There was a wide range of team staffing levels, including part-time staff, from 11.7 to 37.5 , with patient episodes varying from 284 to 900 . Given the government guidelines on staffing
(15 per 150000 population with 300 patient episodes), only half of teams had sufficient staffing ( $88 \%$ in the national survey).

There was a similar input from nurses in Wessex and nationally (100\% v. 98\%), higher input from support workers (100\% v. 70\%), approved mental health professionals ( $83 \%$ v. $49 \%$ ), occupational therapists (50\% v. $30 \%$ ) and psychologists ( $50 \%$ v. $8 \%$ ).

All teams had medical staff input. The proportion composition found was $8.6 \%$, higher than the $5.2 \%$ reported by Middleton et al. ${ }^{4}$ All teams had consultants and $83 \%$ (five teams) had dedicated consultants with other medical staff and half (three teams) had dedicated non-consultant staff.

To ensure crisis resolution and home treatment teams are successful as alternatives to hospital admission, it is vital to have sufficient staff and resources. Teams in Wessex had higher multidisciplinary team staff diversity than the national average, ${ }^{1}$ but only half of them had adequate staffing according to the Department of Health guidance.

1 Onyett S, Linde K, Glover G, Floyd S, Bradley S, Middleton H. Implementation of crisis resolution/home treatment teams in England: national survey 2005-2006. Psychiatr Bull 2008; 32: 374-7.

2 Department of Health. Guidance Statement on Fidelity and Best Practice for Crisis Services. Department of Health, 2007.

3 Department of Health. Mental Health Policy Implementation Guide. Department of Health, 2001.

4 Middleton $\mathrm{H}$, Glover $\mathrm{G}$, Onyett $\mathrm{S}$, Linde K. Crisis resolution/home treatment teams, gate-keeping and the role of the consultant psychiatrist. Psychiatr Bull 2008; 32: 378-9.

Asif M. Bachlani is ST5 in General Adult Psychiatry, Hampshire Partnership Foundation NHS Trust, email: asifbachlani@doctors.org.uk, Geoff Searle is Consultant Psychiatrist, Crisis Team Dorset Healthcare Foundation Trust, UK.

doi: $10.1192 / p b .34 .1 .36 a$

\section{Ethnic distribution of personality disorder}

The prevalence of personality disorder in the UK is between $4 \%$ and $33 \%$ and ranges from $13 \%$ of general practitioner patients to $40-50 \%$ of psychiatric in-patients. There are no figures relating to ethnicity. Ethnic minorities are overrepresented in psychiatric services and especially in compulsory psychiatric care. Black clients are less likely than White clients to be diagnosed with personality disorder and more likely to be diagnosed with schizophrenia. Ethnic minorities are underrepresented in specialist psychotherapy services and are less likely than White clients to be offered counselling or psychological therapy. ${ }^{1}$

In a cross-sectional survey of in-patient data collected over 2 years (2007-2009), we examined the prevalence of personality disorder with regard to ethnic distribution among 6531 psychiatric in-patients. The survey was conducted in Mersey Care National Health Service Trust, a mental healthcare provider in the north-west of England. Ethnicity was divided into two broad categories: White British, and Black and minority ethnic. 
Of the 273 patients (4.2\% of sample) diagnosed with personality disorder, 23 (8.4\%) were Black and minority ethnic patients and 250 (91.6\%) were White British patients. The most common diagnosis was emotionally unstable personality disorder (184 cases).

The results of the survey have led us to further consider why there is underdiagnosis of personality disorder in Black and minority ethnic groups. There is a dearth of research evidence and literature examining personality disorder in those groups and existing evidence refers to studies not representative of the UK population.

National Health Service evidence for mental health in Black and minority ethnic populations states cultural differences exist in the way in which psychological distress is presented, perceived and interpreted, and different cultures develop different responses for coping with psychological stressors. The evidence base on risk and protective factors for mental illness is largely drawn from research on White European or North American populations and hence cannot be generalised to Black and minority ethnic populations. ${ }^{2}$

Cultural and racial stereotyping is a common experience in the context of assessment and decisions concerning treatment, and influences the types of services and diagnoses that Black and minority ethnic individuals seek and receive. A Sainsbury Centre for Mental Health report found that there is a cycle of fear fuelled by prejudice, misunderstanding, misconceptions and sometimes racism in mental health services for this group of users. ${ }^{3}$

The concept of personality disorder in itself poses problems with diagnostic uncertainty and is perceived as a stigmatising label. Attempting to redress the balance with regard to personality disorder within Black and minority ethnic groups is made more difficult due to the pre-existing attitudes towards mental illness in these communities. Mental illness can be regarded as a non-entity, a stigma or a taboo. However, it is not only the patients that need educating but also the professionals responsible for detection and management of personality disorders.

1 Geraghty R, Warren F. Ethnic diversity and equality of access to specialist therapeutic community treatment for severe personality disorder. Psychiatr Bull 2003; 27: 453-6.

2 NHS Evidence-Mental Health. Marginalised groups - black and minority ethnic groups. Mentality, 2004 (http://www.library.nhs.uk/ mentalHealth/ViewResource.aspx?resID=111332).

3 Lanarkshire Mental Health. Minority Ethnic Mental Health Care Lanarkshire Mental Health Needs Assessment Programme, 2005 (http://www.lanarkshirementalhealth.org.uk/Resources/ 20\%20Ethnicity.pdf.)

Asad Raffi is Specialty Registrar Year 6, Mersey Care NHS Trust, email: asad.raffi@hotmail.com, Aisha Malik is General Practice Registrar, North Lancashire Primary Care Trust, UK.

doi: $10.1192 / \mathrm{pb} .34 .1 .36 \mathrm{~b}$

\section{Integrating research into the career of a psychiatrist in the past, present and future?}

Following the maelstrom of Modernising Medical Careers and changes to postgraduate training in the UK, trainees' exposure to research has changed significantly. At an early stage, those interested in a research career apply for a limited number of academic clinical fellow and clinical lecturer posts through academic programmes. The latest version of the Royal College of Psychiatrists' Occasional Paper 65, Specialist Training in Psychiatry, advocates two sessions of 'protected time' for higher trainees for both research and special interest sessions (unlike the four sessions advocated in the past). ${ }^{2}$ Anecdotal feedback from trainees across the country suggests that significant numbers of higher trainees are therefore not conducting research (favouring audit), and although provision is made in the curriculum for research, deaneries are not compelled to enforce this.

Australian colleagues have pointed to this problem in the past ${ }^{3}$ and used the analogy of knowledge of research methods and statistics without conducting actual research being akin to that of practising medicine based solely on theoretical knowledge, without patient contact.

Furthermore, at a time when recruitment into psychiatry is in the spotlight, one of the accepted reasons for students neglecting psychiatry as a career choice (perceived lack of a scientific basis) ${ }^{4}$ may be accentuated.

The ramifications of this shift could be that an entire generation of psychiatrists stop asking (and testing) the clinically relevant questions and that aspiring students do not enjoy the enriching experience of research.

1 Royal College of Psychiatrists. Specialist Training in Psychiatry: A Comprehensive Guide to Training and Assessment in the UK for Trainees and Local Educational Providers. Occasional Paper OP69. Royal College of Psychiatrists, 2009 (http://www.rcpsych.ac.uk/ files/pdfversion/OP69.pdf)

2 Tyrer P. Is research just an optional extra in clinical psychiatry? Invited commentary on ... Research as part of the career of a psychiatrist entering clinical practice. Psychiatr Bull 2009; 33: 273-4.

3 Hay $P$, Mulder R, Boyce $P$. The scientific practitioner in psychiatry for the 21st century. Australas Psychiatry 2003; 11: 442-5.

4 Malhi GS, Parker GB, Parker K, Carr VJ, Kirkby KC, Yellowlees P, et al. Attitudes toward psychiatry among students entering medical school. Acta Psychiatr Scand 2003; 107: 424-9.

Sameer Jauhar is ST5 in General Adult Psychiatry, Hairmyres Hospital, Lanarkshire, Scotland, email: sameer.jauhar@hotmail.com

doi: $10.1192 / p b .34 .1 .37$ 